geral sobre estrutura e propriedades de diferentes ferrites com estrutura tipo perovskite; mostrou como as propriedades de condução mista podem ser conjugadas com os resultados de espectroscopia Mössbauer, permitindo uma melhor compreensão de fenómenos como a ordem de carga, tão vulgares em compostos deste tipo.

$X$ Jean Juraszek (Université de Rouen, France), que fez uma apresentação detalhada sobre a estrutura, as propriedades magnéticas e as aplicações de multicamadas com propriedades de magnetostrição gigante, um tema actual e em expansão.

Para além das palestras convidadas, foram ainda apresentadas 17 comunicações orais e outras 17 sob a forma de poster, sendo de realçar o interesse e a elevada qualidade científica de todos os trabalhos apresentados, amplamente testemunhada pela vivacidade das discussões científicas ocorridas. Para além da adesão de novos investigadores portugueses ao GFSM, este encontro foi também a ocasião para novas e renovadas colaborações entre todos os participantes. É de salientar que estiveram representados 5 dos 7 grupos que actualmente utilizam a espectroscopia de Mössbauer em Portugal.

A qualidade científica do encontro e a forma cuidada como decorreu foram amplamente reconhecidas e apreciadas pelos participantes, nacionais e estrangeiros. A Comissão Organizadora está particularmente satisfeita com o sucesso do encontro e agradece calorosamente o apoio de todos os patrocinadores do evento.

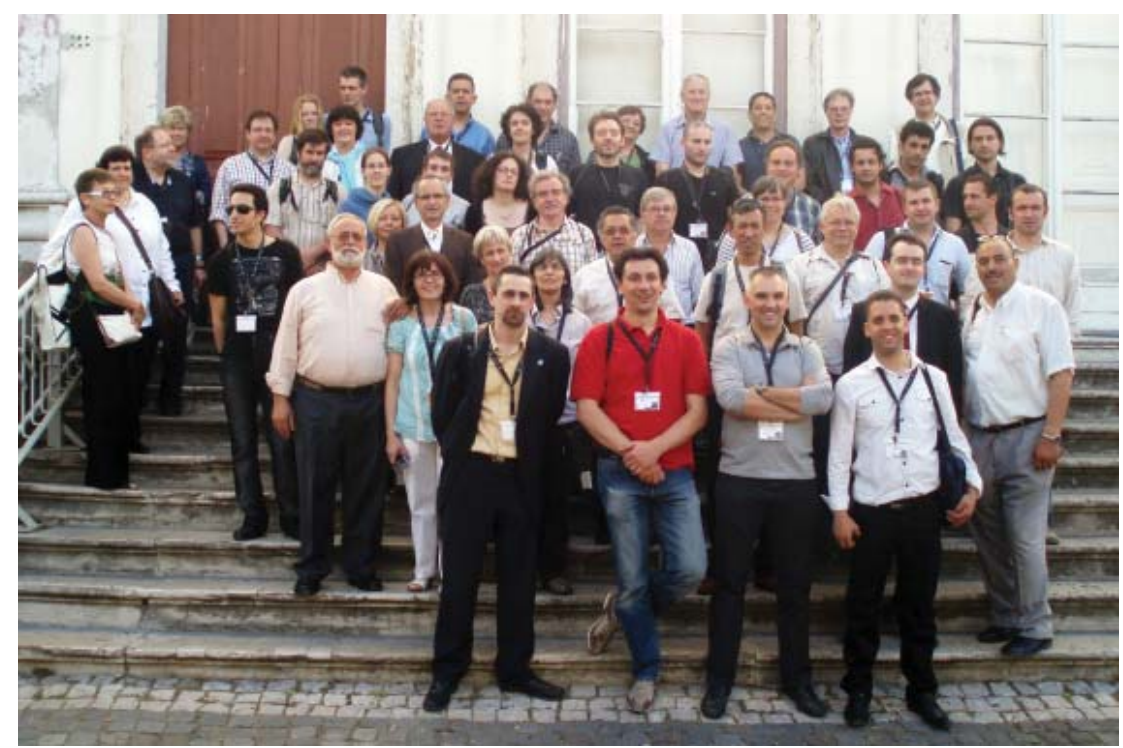

Foto de grupo dos participantes

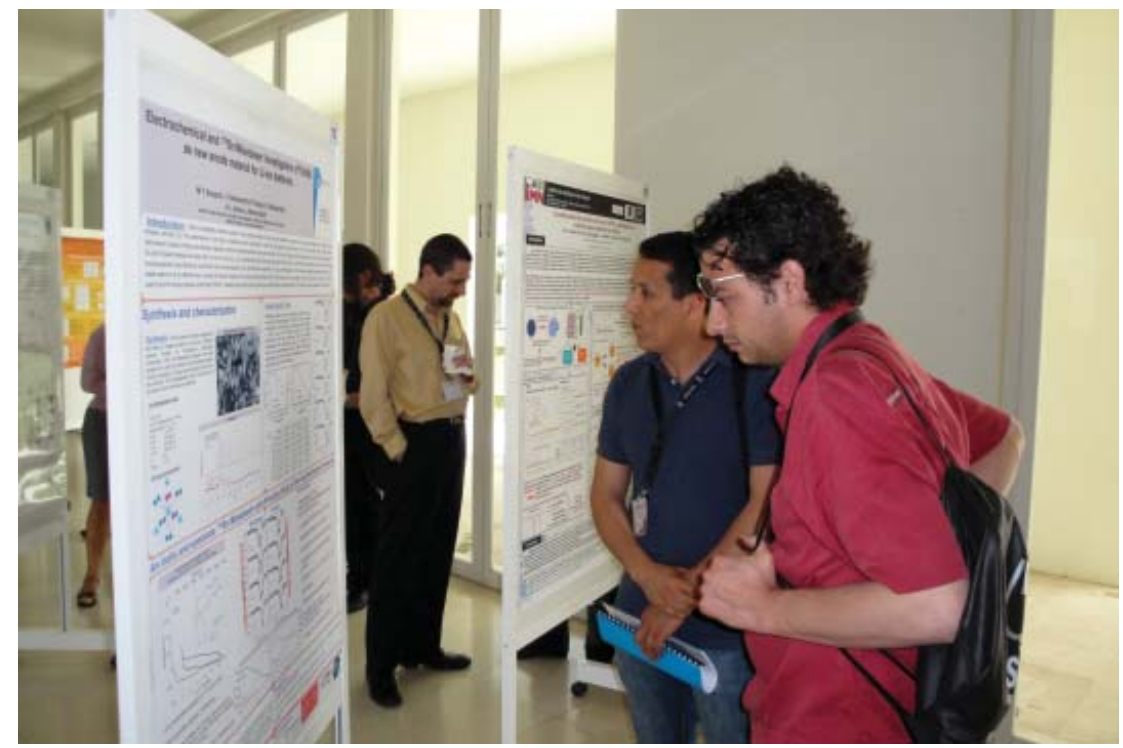

Sessão de Posters

LF, MDC

(Comissão Organizadora)

\title{
Jubilação do Professor Manuel Ribeiro da Silva
}

No próximo dia 30 de Setembro ocorrerá a jubilação do Doutor Manuel A. V. Ribeiro da Silva, Professor Catedrático do Departamento de Química e Bioquímica da Faculdade de Ciências da Universidade do Porto. Nesse dia, o Professor Ribeiro da Silva pro-

\section{Nota Biográfica do Professor Manuel Ribeiro da Silva}

O Professor Doutor Manuel Ribeiro da Silva, licenciou-se em Engenharia ferirá a Última Lição, às onze horas, no Salão Nobre da Reitoria da Universidade. Durante a tarde, decorrerá no Departamento de Química e Bioquímica uma homenagem, sob a forma de um simpósio dedicado à vida e obra daquele professor, que culmi-

Químico-Industrial na Faculdade de Engenharia da Universidade do Porto, em 1965. Doutorou-se em Química (Ph.D.), pela Universidade de Surrey, nará num jantar no Restaurante das Caves Taylor. Todos aqueles que desejem associar-se a esta homenagem poderão contactar o Departamento de Química e Bioquímica da Faculdade de Ciências da Universidade do Porto.

JG

Inglaterra, em 1974. Iniciou a sua actividade docente em 1965, como Assistente de Química da Faculdade de Ciências da Universidade do Porto 
(FCUP), onde é Professor Catedrático de Química, desde 1979. Entre outros cargos de gestão, foi Presidente do Conselho Pedagógico (1974/75) e Presidente do Conselho Directivo e Director da FCUP (1986 - 1998).

Membro da Comissão Instaladora e, posteriormente, da Comissão Directiva do Centro de Investigação em Química da Universidade do Porto (desde 1975), é presentemente o seu Coordenador Científico. Responsável por uma dezena de projectos de in-

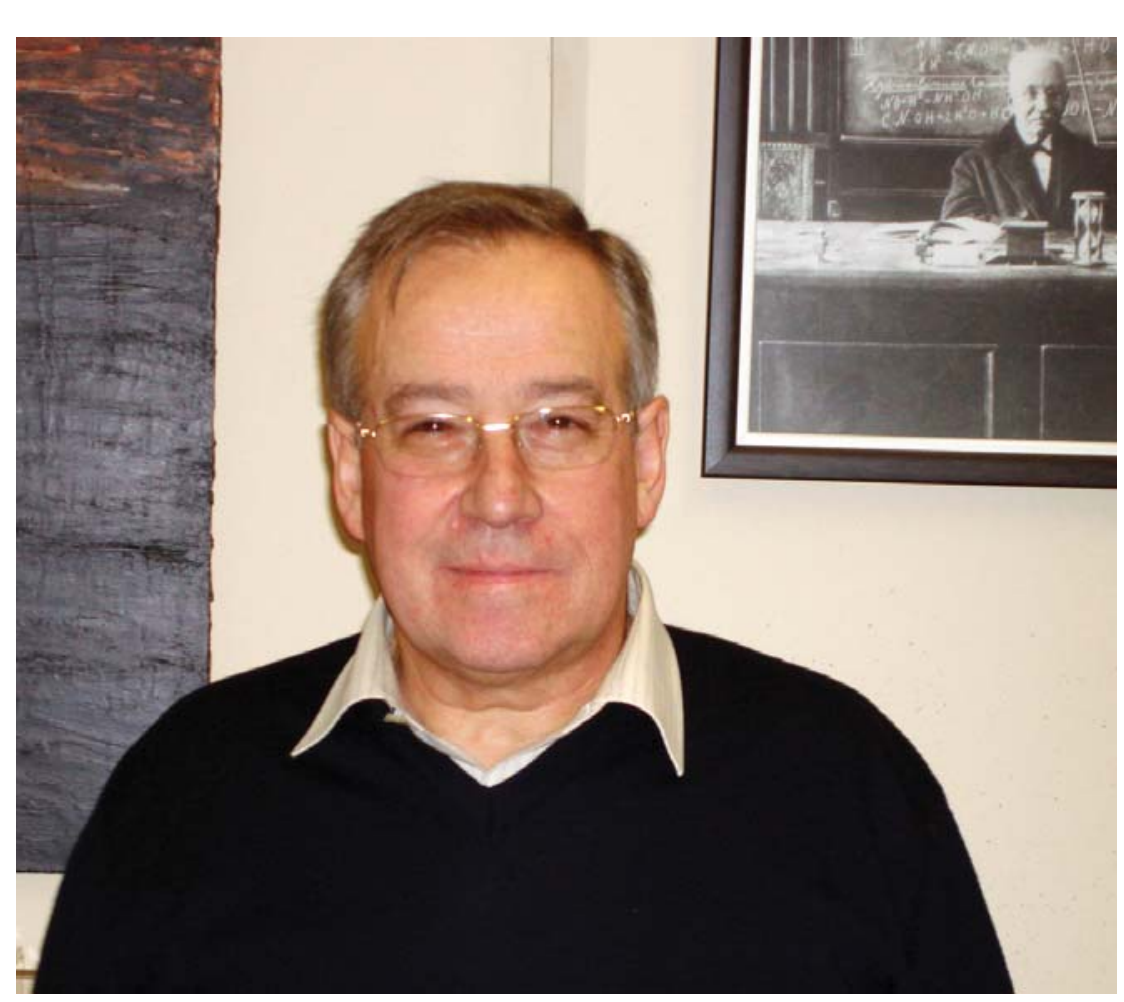

Professor Manuel Ribeiro da Silva sob o olhar do Professor Ferreira da Silva

vestigação financiados por agências nacionais ou internacionais, orientou várias dissertações de doutoramento em Química (14 já concluídas) e vários pós-doutoramentos de investigadores nacionais e estrangeiros.

A sua actividade científica intensa traduz-se em mais de 300 artigos científicos publicados em revistas internacionais $\mathrm{SCl}, 7$ Capítulos de Livros Científicos, cerca de três centenas de Comunicações Científicas (incluindo cerca de 40 Lições Plenárias e Convi- dadas) em Conferências Nacionais e Internacionais.

O Professor Doutor Ribeiro da Silva é "Fellow" da IUPAC (desde 2002), membro do "Advisory Board" do Journal of Chemical Thermodynamics e, em 2006, a Academia das Ciências de Lisboa elegeu-o como "Académico Correspondente da $3^{a}$ Secção-Química”.

Durante a sua carreira recebeu inúmeros prémios e distinções nacionais e internacionais, destacando-se o Diploma e a Medalha Comemorativa do Instituto da Ordem de Lenine da Academia das Ciências da URSS (Química Inorgânica) "pela sua contribuição para o desenvolvimento da Química dos Compostos de Coordenação" (1988), o Prémio e Medalha Ferreira da Silva (2002), atribuído pela Sociedade Portuguesa de Química "pela obra científica produzida em Portugal e em reconhecimento da sua contribuição significativa para o avanço da Química", a W. Swietoslawski Medal of Honour (2003), atribuída pela Polish Society of Calorimetry and Thermal Analysis "pela excepcional actividade científica internacional em termodinâmica e calorimetria", o Prémio Estímulo à Excelência (2004) atribuído pela Fundação para a Ciência e a Tecnologia e o Christensen Award (2009), atribuído pela North American Calorimetry Conference (CALCON), em reconhecimento pela "sua notável e inovadora contribuição científica na área da Calorimetria".

\section{Periódicos de Química Portugueses}

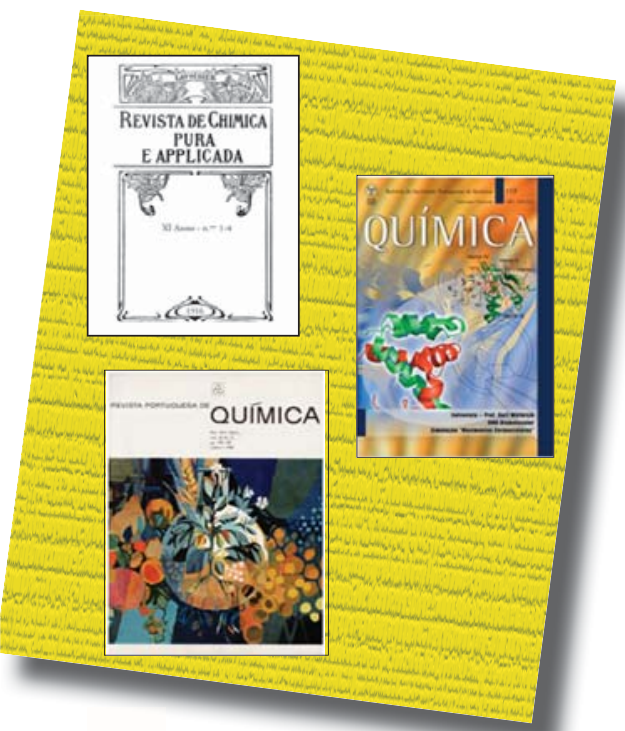

A Sociedade Portuguesa de Química vai digitalizar e colocar on-line todas as suas publicações periódicas, com acesso livre e com possibilidade de pesquisa de conteúdos.

Esta iniciativa insere-se nas comemorações do Ano Internacional da Química (2011) e do Centenário da SPQ (2011-2012). Neste projecto, designado por "Periódicos de Química Portugueses", a SPQ irá disponibilizar os periódicos: Revista de Chimica Pura e Applicada (1905-1956), Revista Portuguesa de Química (1958-1997) e
Química, Boletim da Sociedade Portuguesa de Química (1977-presente), correspondendo a 105 anos de actividade editorial, e a cerca de 23.400 páginas. O Projecto "Periódicos de Química Portugueses", conta com a participação de duas empresas externas, uma de digitalização e outra de elaboração da aplicação de interface e de gestão, e tem o apoio da Fundação Calouste Gulbenkian, que para esse fim concedeu um importante subsídio.

As publicações deverão ficar on-line em Junho de 2011. 